Discussion These findings show that some groups of workers face a higher risk of work-related MSD and that further monitoring and targeted measures are needed to support employers and employees especially at a time of economic recovery.

Full results and description of the methodology can be found at http://www.esri.ie/publications/work-related-illness/

\section{USING GENERAL POPULATION JOB-EXPOSURE MATRIXES TO ESTIMATE WORKPLACE BIOMECHANICAL EXPOSURES: NEW OPPORTUNITIES AND INTERNATIONAL COMPARISONS}

${ }^{1}$ BA Evanoff* ${ }^{2,3}$ A Descatha, ${ }^{1} \mathrm{~S}$ Buckner-Petty, ${ }^{1} \mathrm{AM}$ Dale, ${ }^{4} \mathrm{~J}$ Andersen. ${ }^{1}$ Division of General Medical Sciences, Washington University School of Medicine in St. Louis, St. Louis, MO, USA; 'Inserm, Population-Based Epidemiological Cohorts Unit, UMS 011, F-94807, Villejuif, France; ${ }^{3}$ Versailles St-Quentin University, UMS 011, F-94807, Villejuif, France; ${ }^{4}$ Regional Hospital West Jutland, Department of Occupational Medicine, Herning, Denmark

\subsection{6/oemed-2018-ICOHabstracts.774}

Introduction Job Exposure Matrixes (JEMs) are commonly used in epidemiological studies of chemical and physical hazards; recent work has used JEMs to estimate workplace biomechanical exposures in studies of musculoskeletal disorders (MSDs). We conducted cross-national comparisons of general population JEMs from Denmark, France, and the USA. Prior studies using the Danish and US JEMs showed associations between MSD and workplace exposures to force, repetition, and posture.

Methods JEMs were constructed in the three countries using different methods to estimate workplace biomechanical exposures: Denmark (expert assessment), France (pooling of selfreported exposures from $>28000$ current workers), and the USA (combined methods using O*NET, a national job demands database). Each JEM assigned multiple exposures to workers at the level of the job code. We created cross-walks between the respective national coding schemes (DISCO, PCS, and SOC) to compare estimated exposures at the level of the job.

Results Comparison between the Danish and US JEMs showed fair to moderate agreement for 7 lower extremity exposures across 168 job codes (kappa 0.25 to 0.56 across 7 exposures), and moderate to substantial agreement for 10 shoulder exposures across 336 jobs (kappa 0.38 to 0.77). Similar agreement was found when comparing 8 exposures between the French and American JEMs across 335 job codes. We will report additional analyses now in progress, including the strength of association between MSDs and exposures estimated by different JEMs when applied to the same datasets.

Discussion JEM for biomechanical exposures are a useful and efficient means to estimate workplace biomechanical exposures, particularly in large general population studies where exposure data are otherwise limited. Cross-national comparison studies are a useful methodological step as the use of JEM for studies of MSD continues to increase. Ongoing validation studies will increase the usability of JEMs in providing exposure-response estimates and further guidance for prevention of MSDs.

\section{POST-OFFER/PRE-EMPLOYMENT SCREENING FOR CARPAL TUNNEL SYNDROME AND OTHER MUSCULOSKELETAL DISORDERS: IS IT EFFECTIVE?}

BA Evanoff* , S Buckner-Petty, AM Dale. Division of General Medical Sciences, Washington University School of Medicine in St. Louis, St. Louis, MO, USA

\subsection{6/oemed-2018-ICOHabstracts.775}

Introduction Pre-employment examinations, known as post-offer pre-placement (POPP) tests in the US, are performed by many US employers to prevent work-related musculoskeletal disorders (MSDs) such as carpal tunnel syndrome (CTS). However, there is no strong evidence of effectiveness of such screening. We tested the predictive validity of POPP screening using nerve conduction studies (NCS) to identify future cases of carpal tunnel syndrome (CTS) among manufacturing workers.

Methods We used data from a natural experiment in which 1648 newly hired production workers in a manufacturing plant underwent baseline physical exam and NCS, but were hired regardless of test results. Workers were then followed for up to 5 years; outcomes of CTS and workplace physical exposures in different jobs were obtained from the employer's medical and safety records.

Results There was no association between NCV results at the time of hire and future CTS. Varying the diagnostic cut-offs for determining 'abnormal' NCS did not improve predictive validity. However, workers in jobs with high hand/wrist exposure showed greater risk of CTS than those in low exposed jobs (Relative Risk 2.82; 95\% CI: 1.52 to 5.22).

Discussion NCS and other screening tests for the musculoskeletal system are commonly used in the US as a primary means to reduce or prevent MSDs, despite little evidence that such testing predicts which workers will incur MSDs in the future. Ours is the third study to find that POPP screening is ineffective as a preventive strategy for CTS. Other common testing strategies for MSDs do not satisfy evidence-based criteria, and their use should be scrutinised. Such screening seems a poor use of health and safety resources, which could better be spent on improving work activities to reduce injury risk for the entire worker population.

\section{WORKPLACE PRACTICES AND POLICIES TO PREVENT MSD: DEVELOPING AN IMPLEMENTATION GUIDE}

D Van Eerd*, E Irvin, K Cullen. Institute for Work and Health, Toronto, Canada

\subsection{6/oemed-2018-ICOHabstracts.776}

Introduction Musculoskeletal disorders (MSD) continue to be a major burden for workplaces and workers as well as insurance and health systems. Evidence-based approaches are desired but research-to-practice gaps remain. One reason for gaps is the necessary research of sufficient quality is often not available. However evidence-based practice considers both scientific evidence as well as practitioner expertise. Our objective is to synthesise evidence from the scientific literature, practice evidence (policies and practices), and experiences from stakeholders. 
Methods Scientific evidence from recently published reviews, including a recent review our team completed, will be synthesised. Evidence from practitioners' expertise and worker experiences are being collected using a web-based survey, focus groups, and interviews with representatives from various stakeholder groups from multiple sectors. We are using the Public Health Agency of Canada's best practices portal to structure data collection of workplace practices and policies. We are synthesising the evidence gathered from stakeholders with that from recently published systematic reviews.

Result Recent systematic review results revealed 61 high and medium studies addressing MSD. The studies described 30 different intervention categories. There was strong evidence that resistance training has a positive effect and moderate evidence that stretching, using a feedback mouse, and workstation forearm supports have positive effects. However the level of evidence was too low to make recommendations for many other interventions. The survey and interview/focus groups to collect practice-based evidence are ongoing.

Discussion The presentation will focus on current policies and practices described by our practitioner and workplace audiences as compared to the scientific evidence. The discussion will outline the synthesis of evidence and co-creation (with OHS stakeholders) of a practical guide to help workplaces develop and implement effective practices and policies to prevent MSD and help workers with MSD return to work safely.

\section{ON - LINE ERGONOMIC WEB ASSESSMENTS - A VALUABLE, COST-EFFECTIVE TOOL FOR PREVENTION OF MUSCULO-SKELETAL DISCOMFORT IN GLOBAL CORPORATE OFFICES}

${ }^{1}$ Kishore Madhwani, ${ }^{2} \mathrm{HV}$ Ravimohan, ${ }^{3}$ Nadarajan Guharaja, ${ }^{4}$ Akhtur Salman, ${ }^{5} \mathrm{VR}$ Mohil, Beliappa2. 'Hindustan Unilever Limited, Mumbai, India; ${ }^{2}$ Hindustan Unilever Limited, Bangalore, India; ${ }^{3}$ Unilever Asia Private Limited, Singapore, Singapore; ${ }^{4}$ Unilever Pakistan Private Limited, Lahore, Pakistan; ${ }^{5}$ Hindustan Unilever Limited, Chhindwara, India

\subsection{6/oemed-2018-ICOHabstracts. 777}

Introduction Globally, it is vital to create office ergonomic awareness amongst corporate employees with emphasis on ergonomic arrangement of workstations, maintaining ideal work postures, optimising chair functions and performing desk stretches.Objective is to promote safer working by exploring cost-effective communication methods to achieve behaviour change.

Methods Invitation was sent to all employees to take up online Nordic questionnaire, a screening tool for musculoskeletal symptoms, shared in local languages on 2 occasions - baseline and after 3 months in Unilever offices at Sri Lanka, Singapore and Malaysia. After completing, employee is guided to animation graphics and trained on correct postures and office ergonomics with animation graphics, $n=203$. Study is currently being undertaken in Pakistan and India (results to be shared subsequently).

Results Approximately 10\% employees had some musculoskeletal symptoms. $85 \%$ of the symptomatic had chronic musculoskeletal symptoms of 1 year duration. However, only $40 \%$ of these employees had ongoing symptoms at the time of evaluation (past 7 days). A subsequent 3 months evaluation after web-based intervention showed a significant $35 \%$ decline in ongoing symptoms. Behavioural interventions responsible for this decline were attributable to:
$70 \%$ employees could arrange their workstation ergonomically, as against $49 \%$ pre intervention.

$83 \%$ employees performing desk stretches as against 59\% pre intervention.

$70 \%$ of the employees taking rest breaks as against $65 \%$ pre intervention.

97\% employees reported animation graphics were educative and motivating.

Discussion The web - based evaluation appears to be an excellent, cost-effective method bringing about desired behaviour change in ideal work-posture maintenance. Hence, newer technology using web based animation graphics is a highly efficient tool to create office ergonomics awareness and has the potential to become a best practice in countries where language is a communication barrier and an on-site visit is not feasible.

\section{THEORETICAL IMPACT OF WORKPLACE-BASED PRIMARY PREVENTION OF CARPAL TUNNEL SYNDROME IN A FRENCH REGION: A PILOT STUDY}

\begin{abstract}
${ }^{1} Y$ Roquelaure, ${ }^{1} \mathrm{~A}$ Petit, ${ }^{2} \mathrm{E}$ Chazelle, ${ }^{3} \mathrm{~A}$ Descatha, ${ }^{4} \mathrm{~B}$ Evanoff, ${ }^{1} \mathrm{f}$ Bodin, ${ }^{1,2} \mathrm{~N}$ Fouquet. ${ }^{1}$ INSERM, U1085, IRSET, ESTER Team, University of Angers, Angers, France; ${ }^{2}$ French national public health agency, Direction of Occupational Health, Saint-Maurice, France; ${ }^{3}$ INSERM UMS 011, University Versailles St-Quentin, Versailles, France; ${ }^{4}$ Washington University School of Medicine, Division of General Medical Sciences, St. Louis, USA
\end{abstract}

\subsection{6/oemed-2018-ICOHabstracts. 778}

Introduction To assess the theoretical impact of workplacebased primary interventions designed to reduce exposure to personal and/or work-related risk factors for carpal tunnel syndrome (CTS).

Methods Cases of CTS were assessed using regional hospital discharge records for persons aged 20-59 in 2004. Using work-related attributable fractions (AFEs), we estimated the number of work-related cases of CTS (WR-CTS) in high-risk jobs. We simulated three theoretical scenarios of workplacebased primary prevention for jobs at risk: a mono-component work-centred intervention reducing the incidence of WR-CTS by $10 \%(10 \%-\mathrm{WI})$, and multicomponent global interventions reducing the incidence of all surgical cases of CTS by $5 \%$ and $10 \%$ by targeting personal and work risk factors.

Result Nine jobs at high risk of CTS were identified in the region, amounting to $1,618[1,143-2,233]$ CTS cases, of which 952 [488-1,575] were WR-CTS. The 10\%-WI, 5\% GI and $10 \%$ GI hypothetically prevented 95 [49-158], 81 [57112] and 162 [114-223] CTS cases, respectively. The hypothetical preventive efficiency varied depending on the job. The $10 \%$ GI had the greatest impact regardless of the job. The impact of the $10 \%$-WI interventions was high only in jobs at highest risk and AFEs (e.g. food industry jobs). The 10\%-WI and 5\% GI had a similar impact for moderate-risk jobs (e.g. healthcare jobs).

Discussion This study found that work-related CTS cases were concentrated in several high-risk jobs. Simulated workplacebased WI and GI showed that preventive efficiency varied depending on the intervention design, the number of workers in different jobs and the proportion of work-related CTS. This suggests that prevention efforts to reduce exposure to work-related risk factors should focus on high-risk jobs. Reducing CTS rates will also require strategies to reduce personal risk factors, particularly in jobs with low levels of workrelated risk of CTS. 